\title{
COBERTURA, OCUPAÇÃO DO SOLO E EROSÃO NO ENTORNO DA LAGUNA GUARAÍRAS/RN, BRASIL
}

\author{
E. J. S. GOMES*, I. S. BATISTA, Z. M. C. LIMA \\ Universidade Federal do Rio Grande do Norte \\ erickjordangeo@gmail.com*
}

Submetido 30/12/2016 - Aceito 03/02/2018

DOI: $10.15628 /$ holos. 2018.5509

\section{RESUMO}

As zonas costeiras são espaços bastante dinâmicos e complexos, de elevada fragilidade e instabilidade natural. As intensas modificações acarretadas pelas ações antrópicas no ambiente costeiro são agravantes significativos na acentuação dos processos erosivos. Este artigo objetiva-se analisar a ocupação e cobertura do solo no entorno da Laguna de Guaraíras, RN, associando-os com a acentuação dos processos erosivos locais. Os procedimentos metodológicos adotados pautaram-se na efetivação de pesquisas bibliográfica e de campo, produções cartográficas, análises dos processos erosivos atrelados a cobertura ocupação do solo na área de estudo. Os resultados encontrados demonstram que a área do entorno da laguna vem sendo historicamente ocupada e preenchida pelas mais diversas atividades humanas, Agricultura, Pastagem, área urbana e Carcinicultura são algumas das mais representativas, e sua existência e principalmente a atividade constante causa sérios impactos ao meio ambiente, como a erosão costeira, visivelmente presente e altamente susceptível a ser acentuada.

PALAVRAS-CHAVE: Zona costeira, Cobertura e ocupação do solo, Processos erosivos.

\section{COVERAGE, SOIL OCCUPATION AND EROSION IN THE SURROUNDINGS OF GUARAÍRAS LAGOON / RN, BRAZIL}

\begin{abstract}
Coastal areas are very dynamic and complex spaces of high fragility and natural instability. The intense changes caused by the anthropic actions in the coastal environment are significant aggravating factors in the accentuation of erosion processes. This article aims to analyze soil occupation and cover in the surroundings of Laguna de Guaraíras, RN, associating them with the accentuation of local erosion processes. The methodological procedures adopted were based on the accomplishment of bibliographical and field research,
\end{abstract}

cartographic productions, and analysis of the erosive processes linked to soil cover coverage in the study area. The results show that the area around the lagoon has been historically occupied and filled by the most diverse human activities, Agriculture, Pasture, urban area and Carcinculture are some of the most representative, and its existence and mainly the constant activity causes serious impacts to the environment, such as coastal erosion, visibly present and highly susceptible to be accentuated.

PALAVRAS-CHAVE: Coastal zone, Coverage and land occupation, Erosive processes. 


\section{INTRODUÇÃO}

O uso e a cobertura da terra têm se tornado um tema muito discutido nos diversos níveis do conhecimento, devido às diversas problemáticas que o uso e ocupação desordenados trouxeram ao meio ambiente. Ações desenfreadas a exemplo dos desmatamentos para implantação de agroindústrias, de mineradoras, para a criação de animais, plantações e muitas outras atividades ligadas ao uso e cobertura da terra, se constituem hoje como um dos grandes desafios para as políticas de controle ambientais (Araújo, Teles, \& Lago, 2009).

As zonas costeiras concebidas como "espaço geográfico de interação do ar, do mar e da terra, incluindo seus recursos renováveis ou não, abrangendo uma faixa marítima e outra terrestre" (MMA, 2006, p. 22), possuem alguns dos ambientes mais dinâmicos e instáveis do planeta, na qual o sistema natural e os outros elementos estão subordinados a morfogênese e influenciados pela geodinâmica interna (Tricart, 1977).

Trata-se de um ambiente de formação geológica recente e em constante processo de transformação, tornando-o um dos recortes do espaço geográfico que mais sofre com as alterações adversas dos processos, funções ou componentes ambientais, correspondendo aos impactos ambientais negativos (Sánchez, 2013).

Neste sentido, o estudo da erosão costeira toma no contexto da atualidade importância significativa, tanto para a sociedade, quanto para a economia e a conservação dos ambientes naturais. No Rio Grande do Norte (RN) esse tem se tornado um tema cada vez mais comum, visto que nosso estado apresenta uma extensa zona litorânea em permanente exposição a diversos tipos de processos costeiros, dos quais a erosão toma grande destaque, o que vem a ser altamente prejudicial se houver relação entre a erosão diretamente e as atividades antrópicas.

Consideramos neste trabalho erosão como "um processo mecânico que age em superfície e profundidade, em certos tipos de solo e sob determinadas condições físicas, naturalmente relevantes, tornando-se críticas pela ação catalisadora do homem" (Magalhães, 2001, p. 1). Assim, entendemos a erosão como um processo natural intensificado pela ação antrópica.

Em estudo realizado por Vital (2006) sobre a erosão e a progradação do litoral Norte RioGrandense, ela afira que: a erosão costeira, no RN é condicionada pela dinâmica da circulação costeira; a evolução holocênica da planície costeira; o suprimento sedimentar ineficiente; a construção de estruturas de concreto perpendiculares a linha de costa na zona de praia; e fatores tectônicos. Sabe-se que cerca de $60 \%$ da linha da costa oriental do Estado do Rio Grande do Norte apresenta nítidos processos erosivos, causando sérios danos ambientais e levando prejuízos às atividades econômicas e aos usuários próximos a esta linha de costa (Diniz, 2002).

Partimos da hipótese de que: a forma de ocupação do solo do entorno da Laguna Guaraíras e sua cobertura natural possui relação com a intensificação do processo erosivo na área. Nesta perspectiva, problematizou-se o tema a partir das seguintes questões: Quais as características físicas da área de estudo? Como está espacializada a ocupação do solo do entorno da Laguna Guaraíras - RN? Quais as atividades que mais causam impactos negativos na área? Quais as áreas mais afetadas pelo processo erosivo? 
Para responder tais questionamentos, o objetivo delimitado nesta pesquisa foi analisar a cobertura e ocupação do solo no entorno da Laguna de Guaraíras - RN, associando-os com a acentuação dos processos erosivos locais. Em termos específicos: identificar a caracterização dos elementos físicos da área de estudo; reconhecer a espacialização da ocupação do solo do entorno da Laguna Guaraíras - RN; averiguar quais as atividades que mais causam impactos negativos na área; analisar as áreas mais afetadas pelos processos erosivos.

O trabalho justifica-se pela possibilidade de um retorno social, visto que os gestores da área estudada podem, a partir da observação descritiva da ocupação e da cobertura do solo resolver o problema ou amenizá-lo de forma a beneficiar os moradores locais, guias e até turistas que desta forma incentivam o crescimento da economia dos municípios.

\section{2 ÁREA DE ESTUDO}

A área de pesquisa é a Laguna de Guaraíras, localizada entre os municípios de Goianinha, Arês, Tibau do Sul, Nísia Floresta e Senador Georgino Avelino, no RN (FIGURA 01). Á área escolhida para o trabalho compõe aproximadamente $51 \mathrm{~km}^{2}$ do entorno da laguna, cujo critério de escolha correlacionou-se com o destaque de algumas classes de ocupação do solo que podem causar impacto e degradação no meio ambiente e dessa forma mostram maior representatividade para a pesquisa.

Figura 01: Mapa de localização da área de estudo.

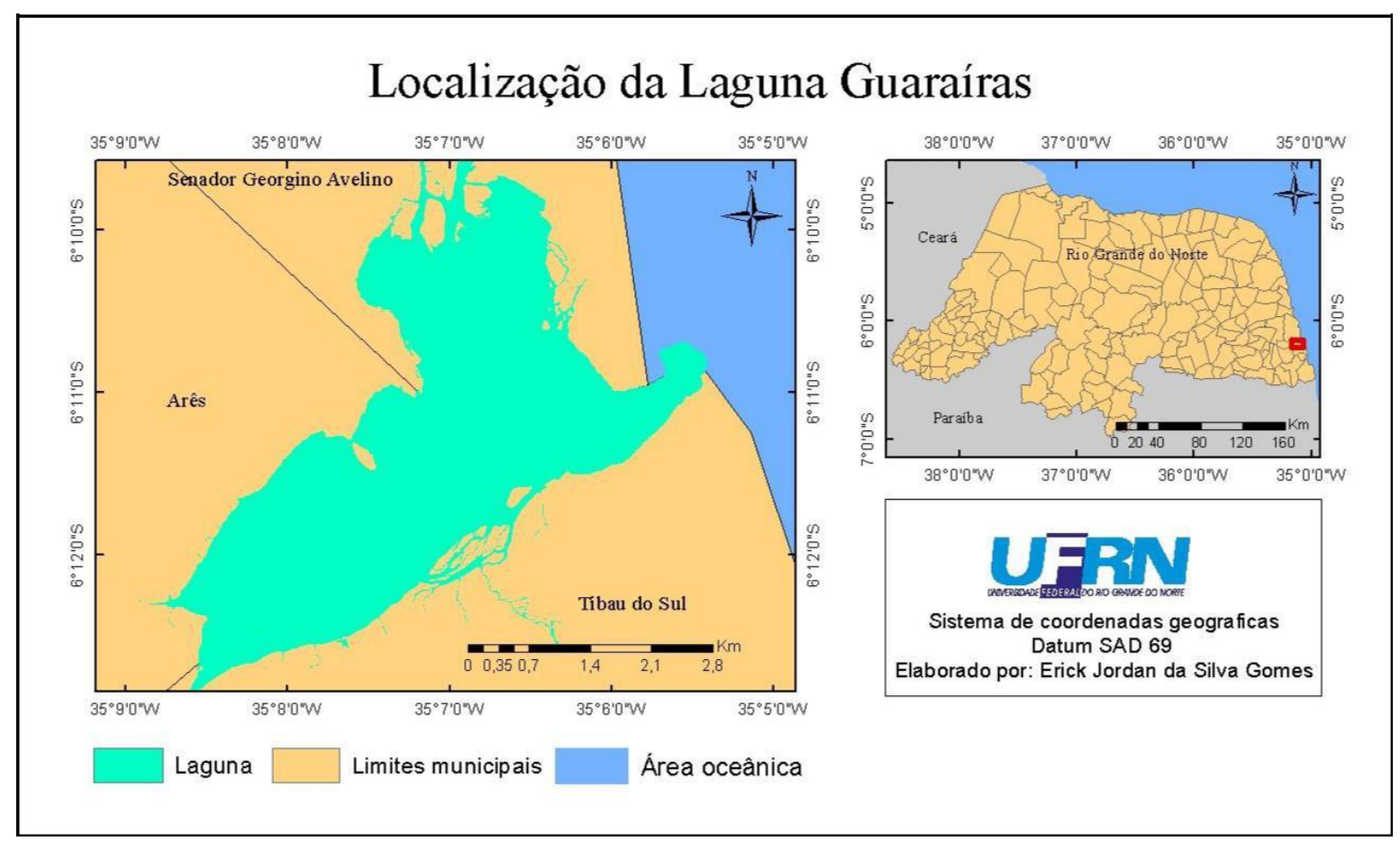

Fonte: IBGE (2015) 


\section{MATERIAIS E MÉTODOS}

De início foi realizada uma pesquisa bibliográfica para embasar teórica e metodologicamente o desenvolver desta pesquisa, assim como, reunir informações essenciais sobre da área de estudo. Realizou-se uma pesquisa prévia onde foram reunidas imagens de satélite e fotos aéreas para subsidiar as análises das várias formas de como o solo do entorno da Laguna Guaraíras está coberto e ocupado e assim ter maior facilidade de identificação de cada feição de acordo com a observação individual delas.

Para realizar de fato uma pesquisa completa efetivaram-se pesquisas de campo com o intuito de reconhecer as unidades da paisagem e validar os mapeamentos realizados, além de observar os impactos ambientais a que a área em questão. Durante a atividade de campo foram necessários à utilização de bússola, câmara digital e um Global Positioning System (GPS - Sistema de Posicionamento Global, na língua vernácula), modelo 79CSX, marca Garmim.

Dados os objetivos do trabalho, a técnica mais apropriada para seguir cada um dos requisitos foi o geoprocessamento. As imagens foram primeiramente adquiridas (Google Earth) e colocadas no software ArcGis 10.2 onde foram georreferenciadas e em seguida foi realizada fase de vetorização, sobre uma escala de 1:5000, de cada feição identificada na imagem disponível identificando assim o equivalente a 11 formas distintas de cobertura ocupação do solo (Quadro 01).

Quadro 01: Sistema de classificação da cobertura e ocupação do uso do solo para área em estudo.

\begin{tabular}{|c|l|}
\hline CLASSES & \multicolumn{1}{c|}{ DESCRIÇÃo } \\
\hline $\begin{array}{c}\text { Pecuária e } \\
\text { Pastagem }\end{array}$ & É a área onde o gado é criado e que dispõe de alimento para o mesmo. \\
\hline $\begin{array}{c}\text { Mata } \\
\text { atlântica }\end{array}$ & $\begin{array}{l}\text { Considerou-se vegetação arbórea do tipo: Floresta estacional, Floresta } \\
\text { Ombrófila Densa e Floresta Ombrófila Aberta. }\end{array}$ \\
\hline $\begin{array}{c}\text { Campo Limpo } \\
\text { Vegetação de } \\
\text { dunas }\end{array}$ & $\begin{array}{l}\text { Também conhecida como restinga, é a vegetação que cobre terrenos } \\
\text { arenosos de origem litorânea e de idade quaternária, formados a partir de } \\
\text { depósitos eólicos. }\end{array}$ \\
\hline
\end{tabular}




\begin{tabular}{|c|c|}
\hline $\begin{array}{l}\text { Campo de } \\
\text { Dunas móveis }\end{array}$ & $\begin{array}{l}\text { São elevações do relevo, formadas a partir de depósitos sedimentares } \\
\text { eólicos e que por não possuírem vegetação ainda são suscetíveis a erosão } \\
\text { e estão expostos a serem transportados pelo vento, modificando sua } \\
\text { dinâmica. }\end{array}$ \\
\hline Zona de Praia & $\begin{array}{l}\text { Área formada por material detrítico, em sua maioria mineral de quartzo e } \\
\text { feldspato, localizada na transição entre a água e o continente, onde sofre } \\
\text { ação direta das ondas. }\end{array}$ \\
\hline Laguna & $\begin{array}{l}\text { As lagunas são ambientes localizados em planícies costeiras e configuram- } \\
\text { se como tal por fazerem algum tipo de contato direto com o mar o que as } \\
\text { diferencia de uma lagoa, podendo ter como obstáculos ilhas-barreiras, } \\
\text { bancos de areia e etc., porém mantendo canais de ligação com a água } \\
\text { salgada. }\end{array}$ \\
\hline Carcinicultura & $\begin{array}{l}\text { É a técnica de criação de camarão em viveiros, para reprodução e } \\
\text { comercialização. }\end{array}$ \\
\hline Manguezal & $\begin{array}{l}\text { É um ecossistema costeiro, localizado na planície de maré que possui água } \\
\text { salgada e são típicas de áreas estuarinas, com intensa diversidade de vida } \\
\text { aquática. }\end{array}$ \\
\hline Área urbana & $\begin{array}{l}\text { Áreas ocupadas pelo ser humano para atividades como: Habitações, } \\
\text { comércios, hotéis e pousadas. }\end{array}$ \\
\hline $\begin{array}{l}\text { Corpos d'água } \\
\text { continentais }\end{array}$ & $\begin{array}{l}\text { São as feições referentes a lagos e lagoas e outros corpos d'água } \\
\text { localizados na área interna do continente. }\end{array}$ \\
\hline
\end{tabular}

Fonte: Organizado pelo autor

\section{RESULTADOS E DISCUSSÕES}

\subsection{Cobertura e ocupação do solo}

As zonas costeiras têm apresentado nos últimos tempos um crescente processo de urbanização, este fator vem corroborando no surgimento e intensificação de impactos ambientais adversos nesses espaços. Esta é a realidade da área de estudo desta pesquisa, trata-se de um ambiente heterogêneo onde a ocupação se dá de diversas formas, desde ocupações atribuídas ao 
ser humano até áreas onde a vegetação e as formações naturais ainda são preservadas (Figura 02), algumas sofrendo com a ação antrópica, outras que ainda resistem tornando a paisagem dos municípios estudados mais atraente tanto para a população quanto para os turistas que visitam periodicamente esse lugar.

Figura 02: Mapa de ocupação e cobertura do solo no entorno da Laguna Guaraíras - RN

\section{Cobertura e ocupação do solo do entorno da Laguna Guaraíras - RN}

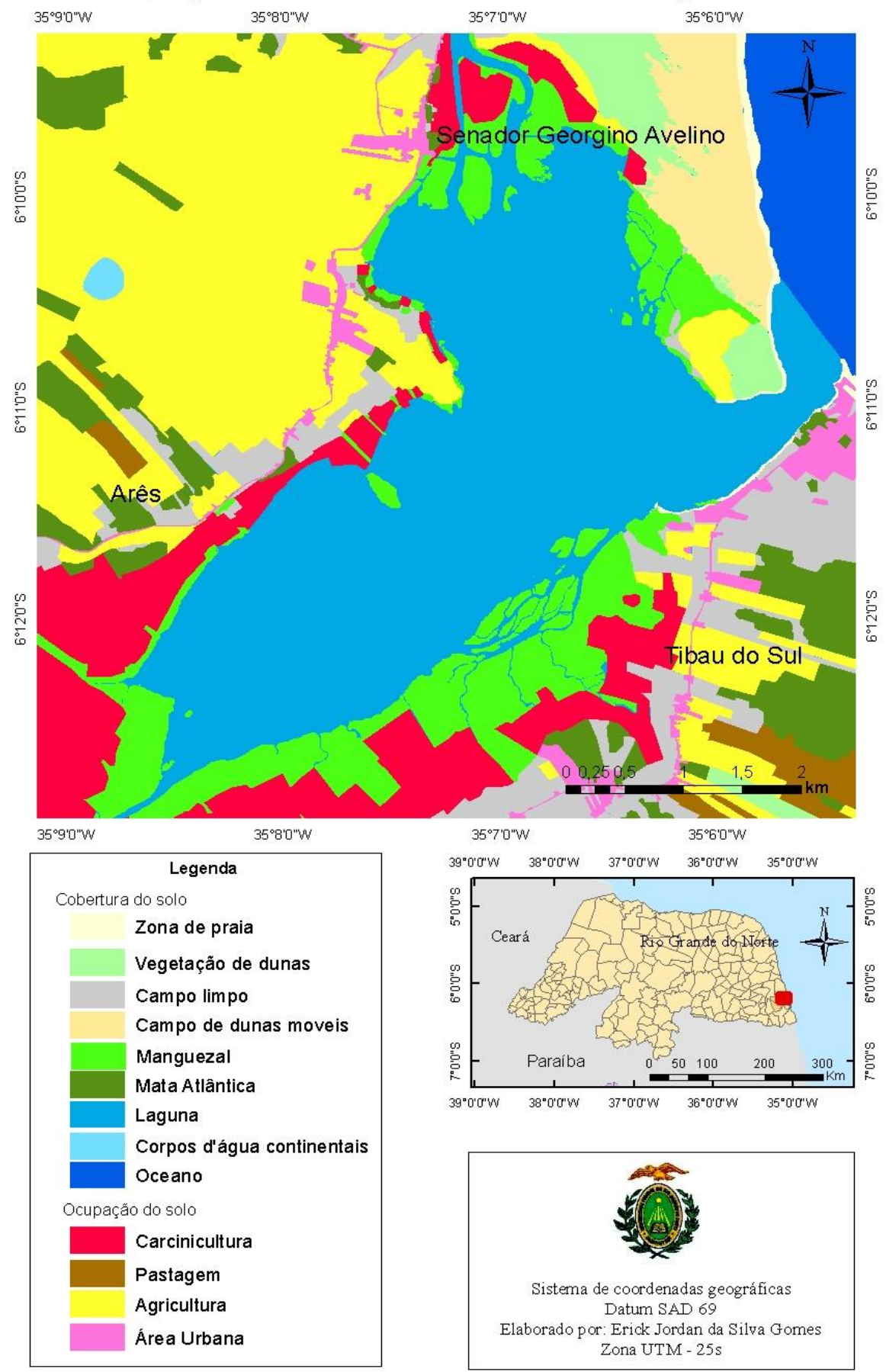


Com o intuito de melhorar a compreensão e a distribuição de cada elemento vetorizado, os dados obtidos foram sintetizados no quadro 02.

Quadro 02: Classes de ocupação do solo.

\begin{tabular}{|c|c|c|}
\hline FEIÇÕES & Área (Km) & Área (\%) \\
\hline COBERTURA DO SOLO & 31,3838 & 61,6 \\
\hline Zona de Praia & 0,2804 & 0,5 \\
\hline Vegetação de dunas & 1,18929 & 2,3 \\
\hline Campo limpo & 3,44644 & 6,8 \\
\hline Campo de dunas móveis & 1,68094 & 3,3 \\
\hline Manguezal & 4,96453 & 9,7 \\
\hline Mata Atlântica & 3,30892 & 6,5 \\
\hline Laguna & 13,90163 & 27,3 \\
\hline Corpos d'água continentais & 0,0961 & 0,2 \\
\hline Oceano & 2,51555 & 5,0 \\
\hline OCUPAÇÃO DO SOLO & 19,6258 & 38,5 \\
\hline Carcinicultura & 5,20015 & 10,2 \\
\hline Pastagem & 0,82458 & 1,6 \\
\hline Agricultura & 12,33619 & 24,2 \\
\hline
\end{tabular}




\begin{tabular}{c|c|c}
\hline Área Urbana & 1,2649 & 2,5 \\
\hline Total & $\mathbf{5 1 , 0 0 9 6 2}$ & $\mathbf{1 0 0 , 0}$ \\
\hline
\end{tabular}

Fonte: Organizado pelo autor.

Naturalmente, o entorno da Laguna ainda possui áreas consideravelmente preservadas, onde são conservadas as vegetações tradicionais no lugar, é o caso da mata atlântica (FIGURA 03), cujos focos estão concentrados principalmente no município de Tibau do Sul. Ao observar a incidência deste bioma nos municípios de Senador Georgino Avelino e Arês é possível identificar uma gradual diminuição, atribuída a maior incidência de áreas de agricultura.

Figura 03: Bioma mata atlântica nas margens da Laguna Guaraíras

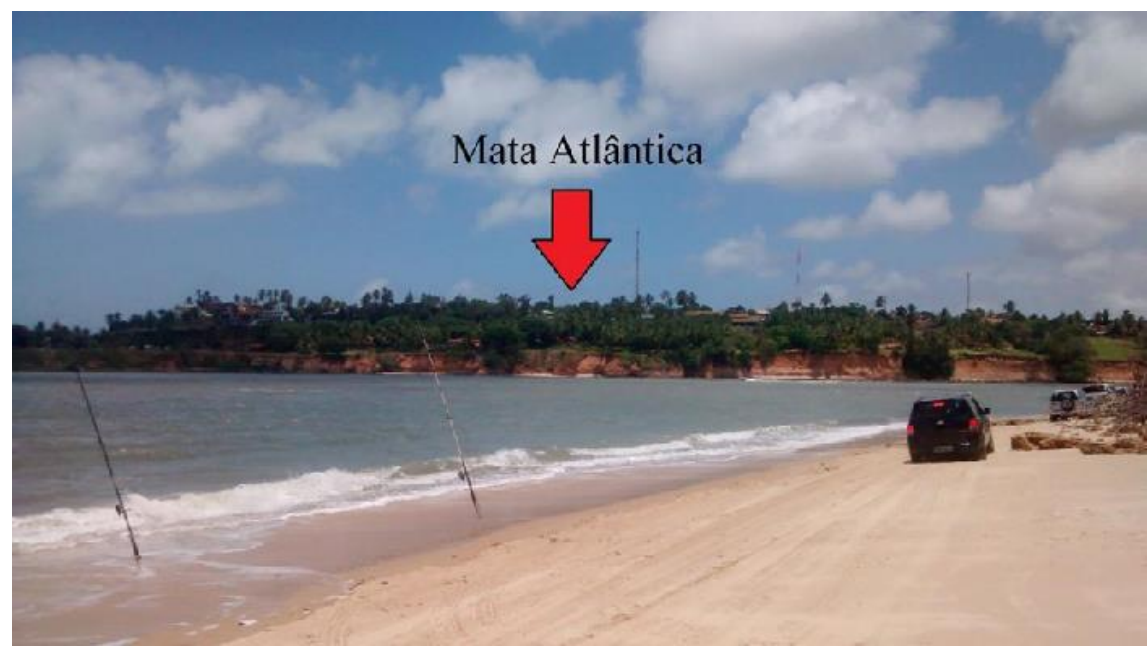

Fonte: Próprio autor (2015).

O Manguezal também se destaca nessa perspectiva visto que é um importante bioma para manutenção da vida aquática de áreas estuarinas, porém, em comparação, com maior representatividade que a mata atlântica, o bioma manguezal ocupa, cerca de 9,7 \%, da área analisada. Visualmente falando, sua incidência maior e nas margens da laguna onde a água salobra propicia o seu desenvolvimento típico em relação a solos, vegetação e biodiversidade aquática.

As áreas de Carcinicultura (criação de camarão) apresentam grande destaque espacial na área estudada, isso porque essa atividade é de importância significativa para a economia local, estadual e até nacional. Localmente, existe claramente uma distinção entre a área ocupada pela Carcinicultura (figura 04) e pelo manguezal, visto que esse tipo de atividade é umas das maiores responsáveis pela destruição e degradação dos manguezais. 


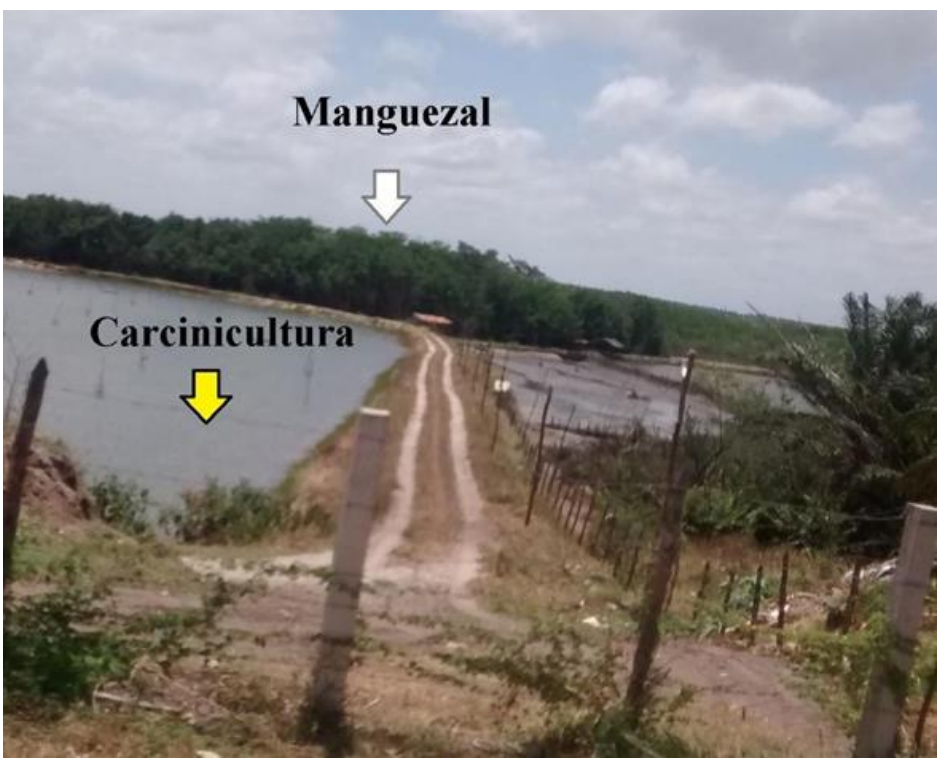

Fonte: Próprio autor (2015).

O motivo dessa comparação é que as áreas ocupadas pelos mangues estão totalmente relacionadas as utilizadas para carcinicultura, ressaltando a relevância de compreender essa diferença, já que a área ocupada por viveiros de camarão na atualidade é maior que os ambientes de mangue ainda preservados. Nota-se essa diferença a partir da comparação entre a porcentagem e a área $\left(\mathrm{km}^{2}\right)$ que elas ocupam, sendo manguezal 9,7\% enquanto que a ocupação do solo preenchida pela criação desse crustáceo é equivalente a 10,2\%. Apesar de pequena a diferença a princípio, se levarmos em conta o quanto de manguezal foi extinto para construção desses viveiros, assim é reconhecido que os números são consideravelmente altos.

Isso faz com que ocorra nesses corpos o processo de assoreamento, que consiste na acumulação de sedimentos, lixo, entulho e outros rejeitos que ao se concentrar no fundo do ambiente aquático, o que prejudicando escoamento das águas, causando assoreamento e eutrofização, dificultando a navegação e a circulação em si, causando em alguns casos consequências quase irreversíveis, diretamente na população que direta ou indiretamente tiram seu sustento da laguna, seja através da pesca ou do turismo (passeios de barco e travessias de balsa).

Por isso, Fabiano (2004) afirma que: "ao mesmo tempo em que a carcinicultura expande a área de Aquicultura e gera emprego, ela enfrenta conflitos com a poluição hídrica, salinização dos lençóis freáticos, a destruição de manguezais, os riscos da introdução de espécies exóticas e difusão de epidemias e a desestruturação das comunidades de pescadores artesanais. 0 funcionamento de fazendas de carcinicultura encontra-se intimamente relacionado à degradação intensa dos ecossistemas costeiros". 
Em um segundo plano, é possível discutir o potencial econômico da Laguna Guaraíras, talvez por abranger três municípios do litoral sul do Rio Grande do Norte com intenso potencial de desenvolvimento. Áreas de pastagem ocupam 1,6\%, essas áreas onde os animais se alimentam estão concentradas principalmente em Tibau do Sul. Apesar de pequena expressão espacial, tem sua importância para os municípios.

A agricultura (Figura 05), sendo ela tanto temporária quanto permanente é um dos maiores destaques da área, ocupando $24,3 \%$ da área estudada é a maior ocupação individual por algum tipo de atividade humana de toda a aérea, principalmente no município de Senador Georgino Avelino, onde uma grande "mancha" de eventos relacionados a plantio e cultivo de alimentos está sendo realizados, principalmente coqueirais e outras árvores frutíferas.

Figura 05: Agricultura (coqueiral)

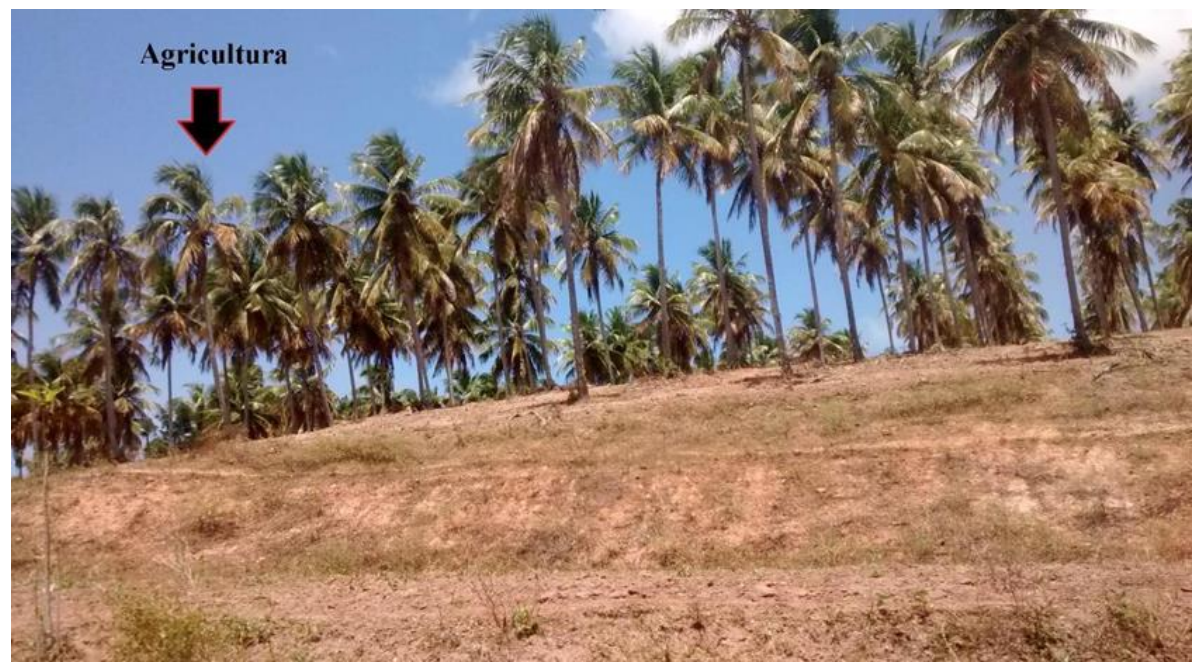

Fonte: Próprio autor (2015).

O homem é um dos maiores agentes transformadores da superfície, é necessária a compreensão destas contribuições humanas integrando as variáveis que influenciam nas dinâmicas associadas aos processos de formação dos ambientes litorâneos (Cardoso, 2017). Nessa perspectiva surgem as edificações (área urbana) (Figura 06), que vem a serem as áreas que o homem se apropriou e construiu algo sobre o solo, sejam pousadas, residências, lojas entre outras, ocupando $2,5 \%$, visto que foram analisadas partes que abrangem 3 municípios ainda assim a maior concentração populacional ainda dá destaque para Tibau do Sul que, por possuir grandes falésias esculpidas em sua zona costeira, possui construções diversas sobre essas formas de relevo. 
Figura 06: Edificações antrópicas (residências)

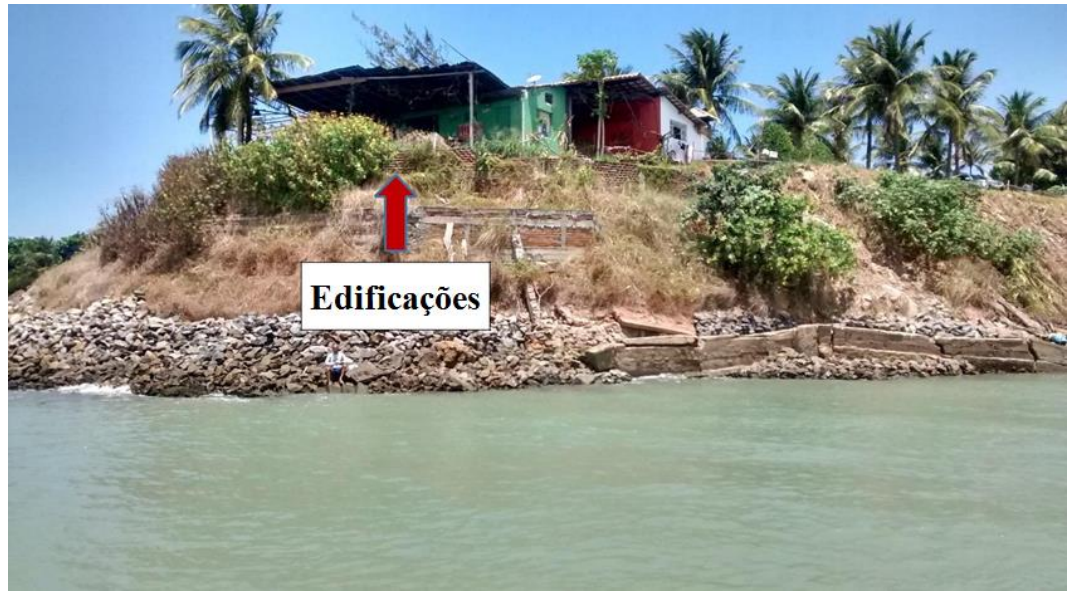

Fonte: Próprio autor (2015)

Como ambientes naturais importantes em ambientes litorâneos é notável a abundância em campos de dunas móveis (Figura 07) que seriam áreas cujas dunas não possuem vegetação fixadora dos sedimentos, os quais estão expostos a serem erodidos pela ação eólica, sendo 3,3\%, ainda se tratando desse tipo de ambiente, é possível observar a vegetação de dunas (Figura 07), também conhecidas como restingas que ocupam $2,3 \%$ da área de estudo.

Figura 07: Vegetação de dunas e Campo de dunas móveis.

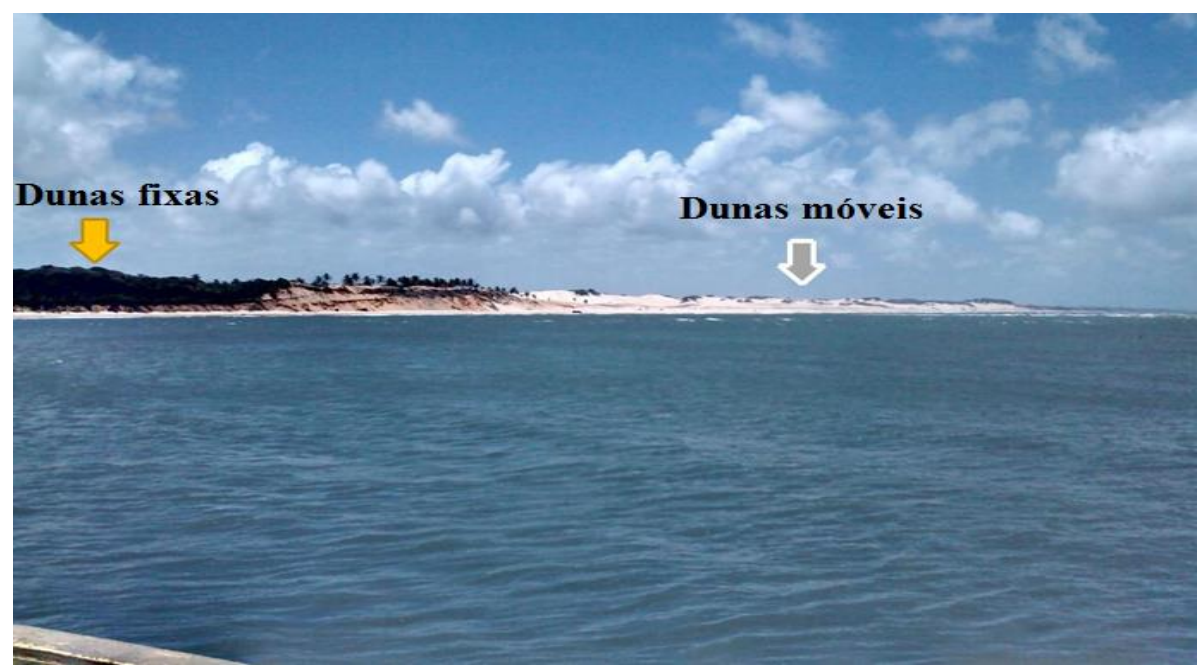

Fonte: Próprio autor (2015).

Uma das mais importantes feições no que diz respeito à compreensão da dinâmica costeira é a praia (Figura 08), com apenas 0,5\% divididos entre Senador Georgino Avelino e Tibau do Sul. Apesar de muito pequena a representatividade em porcentagem, a área é um agente de 
monitoramento significativo para compreensão da energia das ondas, do movimento das marés e de outros fenômenos hidrodinâmicos.

Figura 08: Zona de praia.

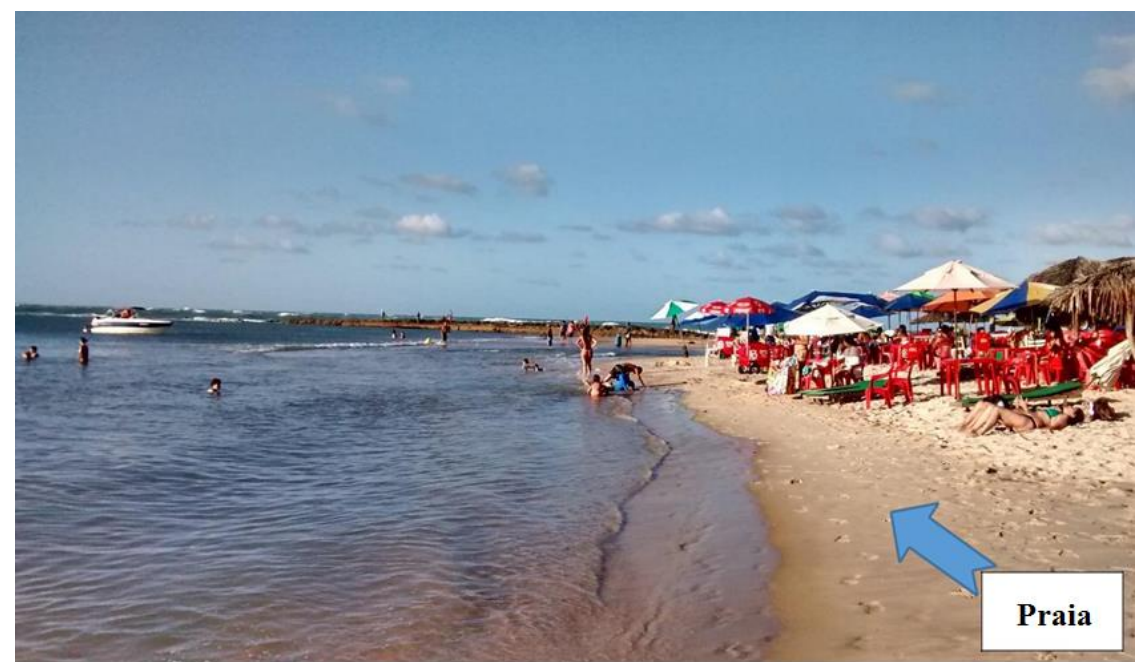

Fonte: Próprio autor (2015).

Quanto aos corpos d'água observados em imagens de satélites e no mapa de ocupação o maior destaque fica de fato com a Laguna Guaraíras, parte de um importante complexo lagunar do $\mathrm{RN}$, área de cerca de $13,90 \mathrm{~km}^{2}$ de onde parte da sociedade local tira seu sustento, através da pesca, do turismo e de outras partes da indústria que dispõe da geração de empregos.

Apesar de a Laguna ser o local com maior disponibilidade de água ainda assim existem outros corpos d'água cuja importância não deve ser diminuída, localizado em Georgino Avelino, muito próximo de áreas cuja agricultura é predominante, apesar de representar apenas $0,2 \%$ de toda a área.

O campo limpo mostrou-se uma das feições mais abundantes na área, sendo 6,8\% da área, lugar onde há predominância de herbáceas, e pouca densidade de vegetação. Finalmente mais uma feição foi registrada, sendo ela o oceano, unicamente pelo fato de ser uma zona litorânea, houve a necessidade de identificar a feição para que ficasse clara a compreensão de cada elemento paisagístico.

\subsection{Erosão costeira}

O crescente uso e ocupação do solo das cidades litorâneas fizeram chegar às margens da linha d'água a pressão urbana, sendo frequentes as notícias de eventos erosivos que atingem as residências, empreendimentos e obras urbanísticas para o lazer e prática de esportes (Maciel, Silva, \& Lima, 2016). 
Para identificar as áreas mais afetadas pela erosão, a etapa de pesquisa de campo foi fundamental, visto que a princípio a observação serviu para descrever os pontos de maior intensidade do processo erosivo nas margens da laguna.

Neste sentido questões naturais e antrópicas podem acarretar a potencialização da erosão costeira. Alguns problemas mais comuns são: edificações em área de pós-praia, retirada de vegetação natural como restinga, mata atlântica e manguezais e aumento relativo do nível do mar. Todos estes fatores apresentarão adversidades futuras devido a sua importância na economia e nos aspectos ambientais (Menezes, 2016)

A primeira evidência, claramente notada, são as raízes expostas (Figura 09) tanto ao lado de Tibau do Sul quanto em Senado Georgino Avelino na parte próxima a desembocadura da laguna. Raízes de árvores de grande porte, cujo movimento de subida e descida da maré têm influenciado diretamente na erosão da escarpa da duna vegetada e tem causado o tombamento dessas árvores.

Figura 09: Erosão costeira na escarpa da duna em Senador Georgino Avelino.

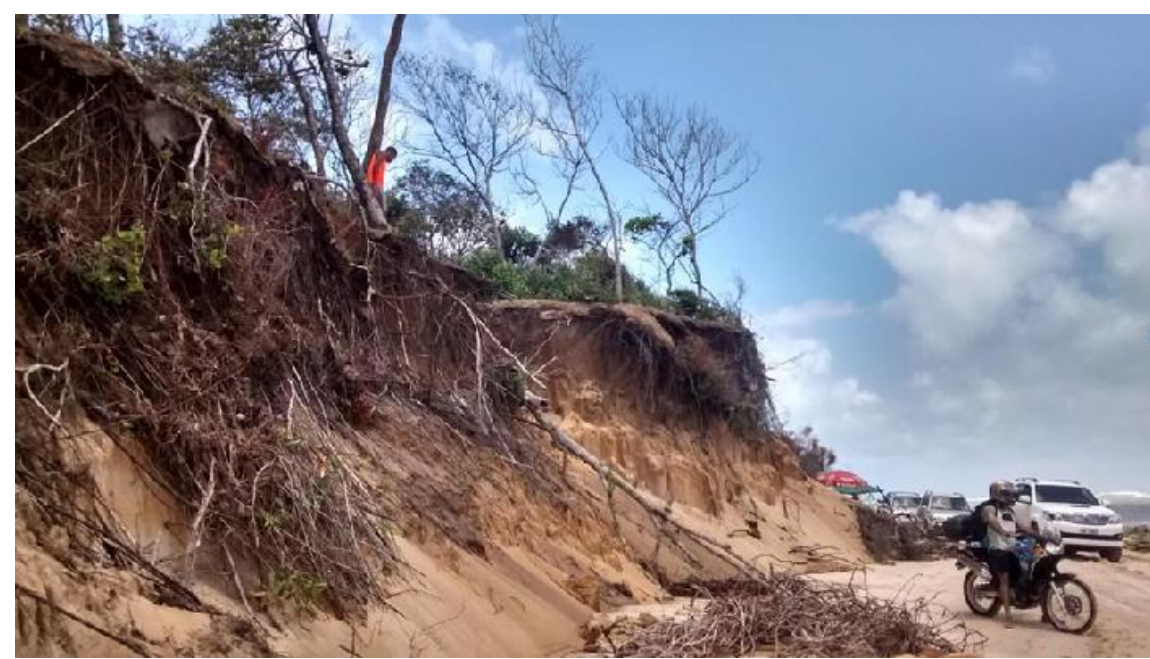

Fonte: Próprio autor (2015).

Em determinados períodos do dia a faixa de praia fica intransitável pela subida da maré, inclusive o transporte de balsa em determinados momentos do dia fica suspenso, pela dificuldade de permanência do lado oposto ao estuário da laguna, onde a paisagem é configurada por ecossistemas costeiros, como praias e dunas (Figura 10). 
Figura 10: Faixa de praia próxima a escarpa da duna vegetada.

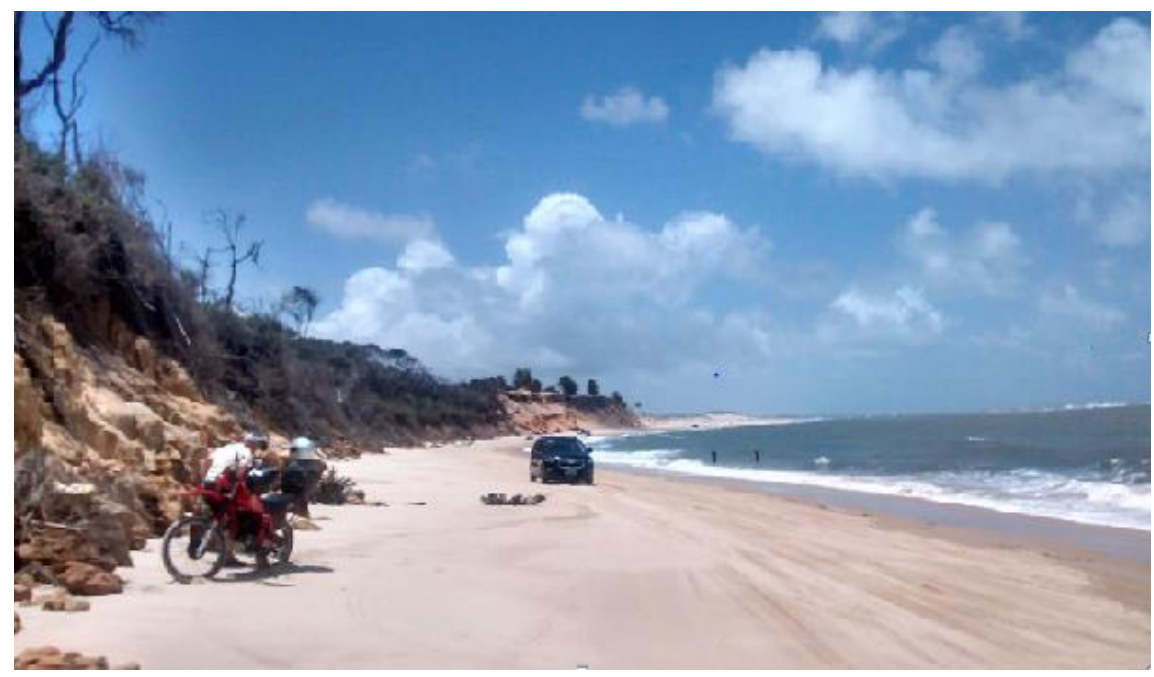

Fonte: Próprio autor (2015).

Outro agente que ressalta que esse evento é constante e persistente é o enrocamento (Figura 11) de diversas áreas da praia, técnica que consiste na colocação de rochas em áreas cuja erosão avançou mais que o estimado, com o intuito de conter ou minimizar as consequências deste fenômeno natural de diminuição do aporte de sedimentos, que ao serem erodidos são transportados para dentro da laguna causando assim o assoreamento da mesma e o surgimento de bancos de areia.

Figura 11: Enrocamento e construção de muros na margem da laguna.

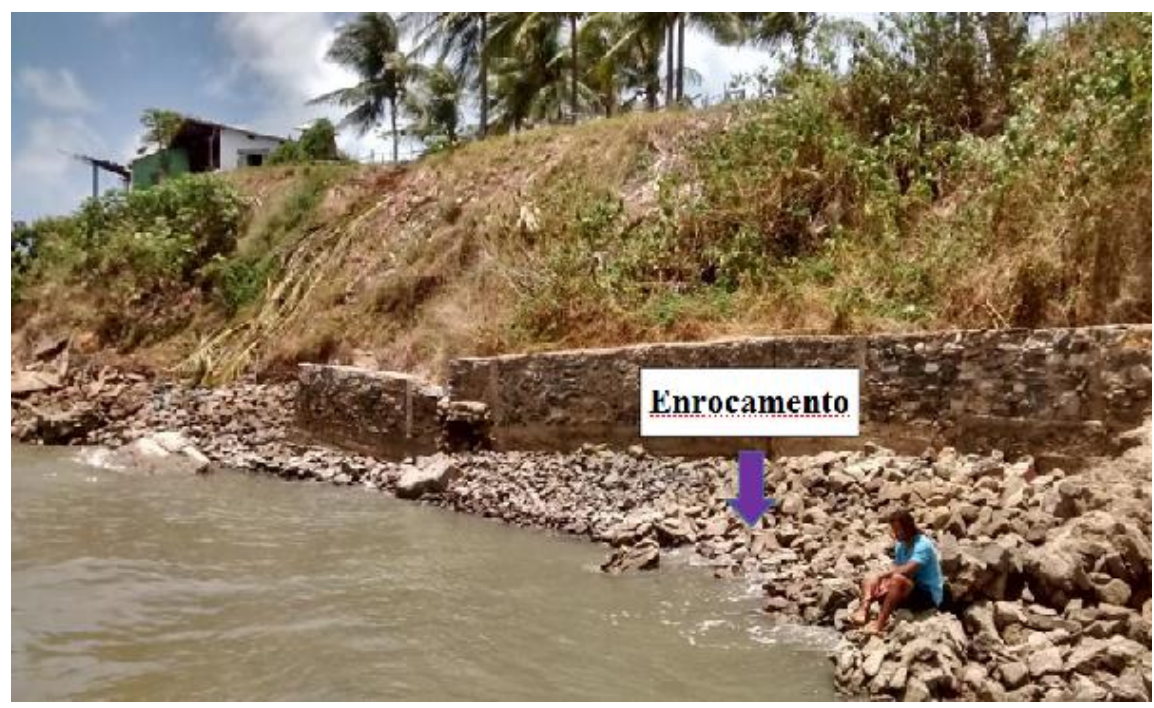

Fonte: Próprio autor (2015). 
Essa forma de contenção ocorre na parte mais próxima ao estuário, onde a faixa de praia corre o risco de desaparecer, caso a intensidade da erosão permaneça alta e as medidas de diminuir a ação desse fenômeno sejam ineficazes.

\section{CONSIDERAÇÕES FINAIS}

As lagunas são ambientes de sedimentação bastante dinâmicos. Esses ambientes envolvem uma série de possibilidades de aproveitamento pelo ser humano, porém possui ecossistemas sensíveis às ações antrópicas e muito úteis se usados sustentavelmente.

Por esse motivo surge a necessidade de conservação e preservação desses ambientes. Quando a ocupação ocorre desordenada tal ambiente se desestabiliza e perde suas características naturais, podendo gerar consequências graves a sobrevivência dos ecossistemas existentes e até mesmo à sociedade.

As técnicas de geoprocessamento e sensoriamento remoto foram usados como ferramentas metodológicas significativas para a realização do trabalho, desde o início até a fase final de elaboração da monografia. A partir de imagens de possibilitou uma maior visibilidade e observação ampla do lugar a ser analisado. O geoprocessamento é uma importante ferramenta tanto para georreferenciamento de imagens quanto para o registro de feições individuais, possibilitando aos órgãos públicos pensar e planejar de acordo com as necessidades da sociedade.

A laguna Guaraíras possui uma ocupação de seu entorno de forma desordenada, motivada principalmente a partir da apropriação histórica do ser humano sobre os espaços. Como mostrou o trabalho, Agricultura, Pastagem, área urbana e Carcinicultura são algumas das formas de ocupação do solo identificadas nesse trabalho.

No caso das áreas urbanas, construções sob a falésia são em sua maioria irregulares o que aumenta a probabilidade de incidentes resultantes da erosão, pelos mais variados fatores.

Pastagens, agricultura e carcinicultura, são formas que o homem encontrou para se aproveitar de recursos naturais e ampliar sua renda, porém são formas de exploração que devem ser muito cuidadosas, já que pastagem e agricultura em algumas vezes se aproveitam do sistema fluvial mais próximo para buscar água para irrigação e para fornecer água para o gado, enquanto a carcinicultura degrada os manguezais para construir os viveiros.

Todas essas formas de ocupação podem gerar consequências graves para a zona costeira, principalmente no que tange aos processos erosivos nessa área, sabendo disso, surge nessa perspectiva um indicativo de pesquisa, a partir da necessidade de identificar o quão vulnerável é tal ambiente, o balanço sedimentar das praias, o percentual erosivo das dunas e assim poder prever qual a tendência do ambiente para o futuro, para tal, a pesquisa de ocupação já realizada pode ser referência para a compreensão desse fenômeno.

O estudo mostrou que a partir realização de um mapeamento de ocupação e da cobertura do solo, foi possível localizar e distinguir cada elemento que compõe a superfície, contribuindo diretamente para o crescimento econômico de cada município e principalmente o desenvolvimento da sociedade. 
Certamente conhecer esse tipo de informação possibilita que o poder público das gestões municipais e estadual possa realizar políticas de conservação dos biomas que estão sendo degradados e tomar medidas compensatórias para que haja um monitoramento da dinâmica ambiental, permitindo que os recursos naturais existam sobre o ambiente, prevenindo assim a destruição dos ambientes a curto prazo por um desordenado uso de cada um deles.

Políticas interventivas como: Educação ambiental, preservação e reflorestamento das áreas degradadas são algumas das formas de conservar o meio ambiente em questão, reorganizar e de fato planejar com consciência ambiental.

Ao fim torna-se relevante esse estudo como forma de referência, para que futuramente os trabalhos que serão realizados possam pensar tal área como um todo de forma a sempre relacionar a sociedade com o meio físico.

\section{REFERÊNCIAS}

Araújo, E.P., Teles, M.G.L., Lago, W.J.S. (2009). Delimitação das bacias hidrográficas da Ilha do Maranhão a partir de dados SRTM. In: Simpósio Brasileiro De Sensoriamento Remoto, XIV, 2009, Natal. Anais. Natal: 2009. p.4631-4638.

Diniz, R.F. (2002). A erosão costeira ao longo do litoral oriental do Rio Grande do Norte: causas, consequências e influência nos processos de uso e ocupação da região costeira. Tese (Doutorado em Geociências), Universidade Federal da Bahia/Instituto de Geociências, Salvador.

Cardoso, L.R. (2017). Análise evolutiva geológico-geomorfológica e uso e cobertura do solo da planície costeira e zona litorânea do entorno da laguna das gaivotas, ilha de Santa Catarina, SC, Brasil. Trabalho de Conclusão de Curso (graduação em geografia), Universidade Federal de Santa Catarina, Centro de Filosofia e Ciências Humanas.

Fabiano, R.B. (2004). Conflitos socioambientais e gestão integrada e sustentável de recursos pesqueiros. Dissertação (Mestrado em Sociologia Política), Universidade Federal de Santa Catarina, Florianópolis.

IBGE. (2013). Instituto Brasileiro de Geografia e Estatística. Manual técnico de uso da terra. 3a Ed. Rio de Janeiro: IBGE.

Maciel, A.B.C., Silva, R.V.M., Lima, Z.M.C. (2016). Processo erosivo e gestão costeira: Estudo de Caso da Praia de Ponta Negra, Natal/RN, Revista OKARA: Geografia em debate, 10(3), 429452.

Magalhães, R.A. (2001). Erosão: definições, tipos e formas de controle. In: VII Simpósio Nacional de Controle de Erosão Goiânia (GO), 03 a 06 de maio. 
Menezes, A.F. (2016). Análise da vulnerabilidade à erosão costeira no estado de Pernambuco através de indicadores ambientais e antrópicos. Dissertação (Mestrado), Universidade Federal de Pernambuco, Programa de Pós-Graduação Geociências.

MMA. (2006). Ministério do meio ambiente, Ministério do planejamento, orçamento e gestão. Projeto Orla: fundamentos para gestão integrada. Brasília: MMA.

Sanchez, L.E. (2013). Avaliação de impacto ambiental: conceitos e métodos. 2a ed. São Paulo: Oficina de Textos.

Tricart, J. (1977). Ecodinâmica. Rio de Janeiro: IBGE, SUPREN.

Vital, H. (2005). Erosão e Progradação no litoral do Rio Grande do Norte. In: Muehe, D. Erosão e progradação do litoral brasileiro. Brasília: Ministério do Meio Ambiente, p.159-176. 